\title{
An Unexpected Oxidation in the Generation of Cyclopenta[c]piperidines by Ring-Closing Metathesis
}

\author{
Mercedes Amat, ${ }^{*}$ Elisa Brunaccini, Begoña Checa, Maria Pérez, \\ Núria Llor, and Joan Bosch*
}

Laboratory of Organic Chemistry, Faculty of Pharmacy, and Institute of Biomedicine (IBUB), University of Barcelona, 08028 Barcelona, Spain

joanbosch@ub.edu, amat@ub.edu

Received Date (will be automatically inserted after manuscript is accepted)

\section{ABSTRACT}
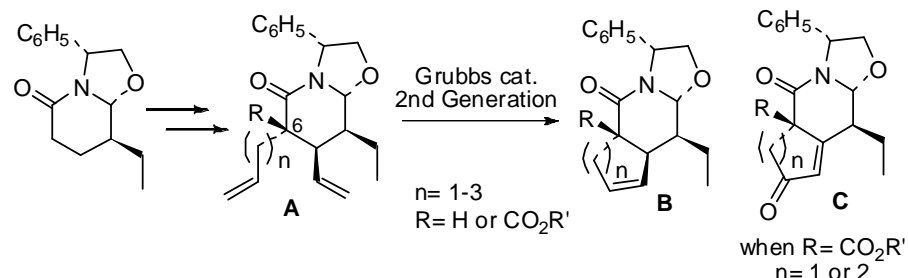

when $\mathrm{R}=\mathrm{CO}_{2} \mathrm{R}$
$\mathrm{n}=1$ or 2

Ring-closing metathesis reaction of dienes $A\left(n=1, R=C_{2} R^{\prime}\right)$ leads to fused cyclopentenones $C$ instead of the expected cyclopentene derivatives $B$. RCM reaction of the other dienes $A$ takes place satisfactorily, affording the expected fused cycloalkene derivatives $B$. Cyclohexene $B\left(n=2, R=C_{2} R^{\prime}\right)$ also undergoes oxidation to the corresponding cyclohexenone $\mathbf{C}$.

Chiral nonracemic aminoalcohol-derived oxazolopiperidone lactams have proven to be versatile scaffolds for the enantioselective synthesis of piperidinecontaining alkaloids and bioactive compounds. ${ }^{1}$ These

${ }^{1}$ For reviews, see: (a) Romo, D.; Meyers, A. I. Tetrahedron 1991, 47, 9503-9569. (b) Meyers, A. I.; Brengel, G. P. Chem. Commun. 1997, 1-8. (c) Groaning, M. D.; Meyers, A. I. Tetrahedron 2000, 56, 9843-9873. (d) Escolano, C.; Amat, M; Bosch, J. Chem Eur J. 2006, 12, 81988207. For more recent work, see: (e) Amat, M.; Pérez, M.; Minaglia, A. T.; Peretto, B.; Bosch, J. Tetrahedron 2007, 63, 5839-5848. (f) Amat, M.; Lozano, O.; Escolano, C.; Molins, E.; Bosch, J. J. Org. Chem. 2007, 72, 4431-4439. (g) Amat, M.; Santos, M. M. M.; Bassas, O.; Llor, N.; Escolano, C.; Gómez-Esqué, A.; Molins, E.; Allin, S. M.; McKee, V.; Bosch, J. J. Org. Chem. 2007, 72, 5193-5201. (h) Amat, M.; Pérez, M.; Minaglia, A. T.; Bosch, J. J. Org. Chem. 2008, 73, 6920-6923. (i) Amat, M.; Griera, R.; Fabregat, R.; Molins, E.; Bosch, J. Angew. Chem. Int. Ed. 2008, 47, 3348-3351. (j) Amat, M.; Fabregat, R.; Griera, R.; Bosch, J. J. Org. Chem. 2009, 74, 1794-1797. (k) Amat, M.; Gómez-Esqué, A.; Escolano, C.; Santos, M. M. M.; Molins, E.; Bosch, J. J. Org. Chem. 2009, 74, 1205-1211. (l) Amat, M.; Checa, B.; Llor, N.; Molins, E.; Bosch, J. Chem. Commun. 2009, 2935-2937. conceptually simple enantiopure molecules bear tactically versatile functionality that enables them to be elaborated into a great diversity of targets.

To further expand the scope of our enantiomeric scaffolding strategy ${ }^{2}$ for the construction of enantiopure polysubstituted piperidine libraries, we devised a general route to highly substituted piperidines bearing a five-, six-, or seven-membered carbocyclic ring cis fused on the $c$ side of the heterocycle. The key steps would be a stereoselective conjugate addition of a vinyl residue to an activated unsaturated lactam already bearing an alkyl substituent at the $\beta$-position of the piperidine ring, a stereoselective alkylation of the resulting $\beta$-oxo ester with unsaturated chains of different length, a ring-closing olefin

\footnotetext{
${ }^{2}$ Coombs, T. C.; Lee, M. D.; Wong, H.; Armstrong, M.; Cheng, B.; Chen, W.; Moretto, A. F.; Liebeskind, L. S. J. Org. Chem. 2008, 73, $882-888$.
} 
metathesis (RCM) from the resulting dienes, and finally the reductive removal of the chiral inductor. We report here an unexpected oxidation after ring-closing metathesis in the cyclopenta- and cyclohexa[c]piperidine series.

Scheme 1 outlines the preparation of the starting dienes 3 from the known ${ }^{3}$ lactam 1 . The conjugate addition of the vinyl group was accomplished in excellent chemical yield and complete exo-facial selectivity, cis with respect to the ethyl substituent, as a consequence of the stereoelectronic control. ${ }^{4}$ A subsequent alkylation of the resulting mixture of C-6 epimeric lactams 2 with allyl bromide, 3-butenyl bromide or 4-pentenyl bromide stereoselectively afforded dienes $\mathbf{3}$ as single stereoisomers.

Scheme 1. Enantioselective Synthesis of the Starting Dienes 3

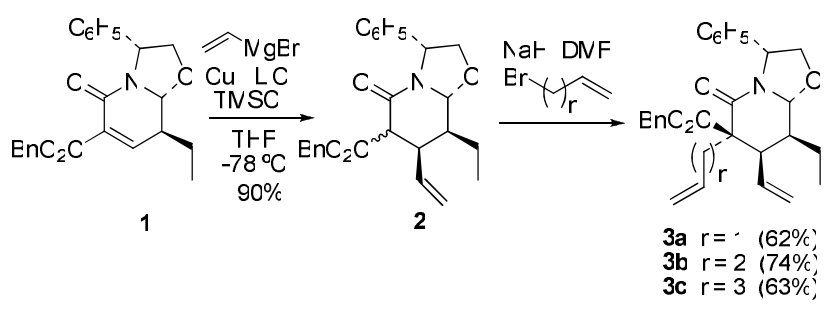

Quite surprisingly, RCM reaction ${ }^{5}$ of lactam 3a catalyzed by the second-generation Grubbs catalyst in refluxing toluene resulted in the formation of enone $\mathbf{4 a}$ in $58 \%$ yield, instead of the expected product $\mathbf{5 a}$ (Scheme 2). A similar result was obtained when the reaction was carried out under Ar atmosphere. At lower temperatures (Ar, $\mathrm{CH}_{2} \mathrm{Cl}_{2}$, rt), most of the starting diene was recovered unchanged and only trace amounts of enone $\mathbf{4 a}$ were detected. ${ }^{6}$ However, when the reaction was carried out in the dark under the last conditions, minor amounts of the expected cyclopentene derivative 5a were detected (NMR) after careful flash chromatography (under Ar in the dark).

In contrast, RCM reactions took place satisfactorily, with no oxidation products being observed, from dienes $\mathbf{3 b}$ $\left(\mathrm{CH}_{2} \mathrm{Cl}_{2}\right.$, rt) and 3c (toluene, reflux; no reaction was observed at $\mathrm{rt}$ in $\mathrm{CH}_{2} \mathrm{Cl}_{2}$ solution) to give in excellent yields the respective tricyclic lactams $\mathbf{5 b}$ and $\mathbf{5 c}$, which were converted to substituted perhydroisoquinoline $\mathbf{7 b}$ and perhydrocyclohepta[c]pyridine $7 \mathbf{c}$ by $\mathrm{LiAlH}_{4}$ reduction followed by catalytic debenzylation (Scheme 3). However,

3 Amat, M.; Pérez, M.; Llor, N.; Bosch, J.; Lago, E.; Molins, E. Org. Lett. 2001, 3, 611-614.

(a) Deslongchamps, P. Stereoelectronic Effects in Organic Chemistry; Pergamon Press: Oxford, 1983, p 221. (b) Perlmutter, P. Conjugate Addition Reactions in Organic Synthesis; Pergamon Press: Oxford, 1992, p 25.

5 (a) Handbook of Metathesis; Grubbs, R. H., Ed; Wiley-VCH: Weinheim, 2003; volumes 1-3. (b) Felpin, F.-X.; Lebreton, J. Eur. J. Org. Chem. 2003, 3693-3712. (c) Deiters, A.; Martin, S. F. Chem. Rev. 2004, 104, 2199-2238.

6 The residual oxygen in the solvent and/or the manipulation during work-up and column chromatography purification could account for the observed oxidation.
Scheme 2. Unexpected Oxidation in the Cyclopenta $[c]$ piperidine Series

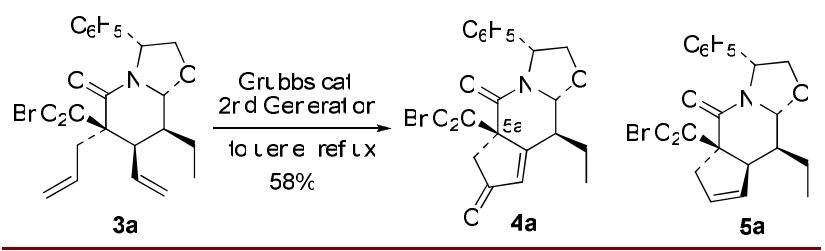

interestingly, refluxing (12 h) a toluene solution of $\mathbf{5 b}$ in an open vessel resulted in a clean oxidation to give the fused cyclohexenone derivative $\mathbf{4 b}$ in $77 \%$ yield. Fused cycloheptene derivative $\mathbf{5 c}$ was recovered unchanged after a similar treatment.

Scheme 3. Ring-Closing Metathesis Reactions from Dienes $\mathbf{3 b , c}$

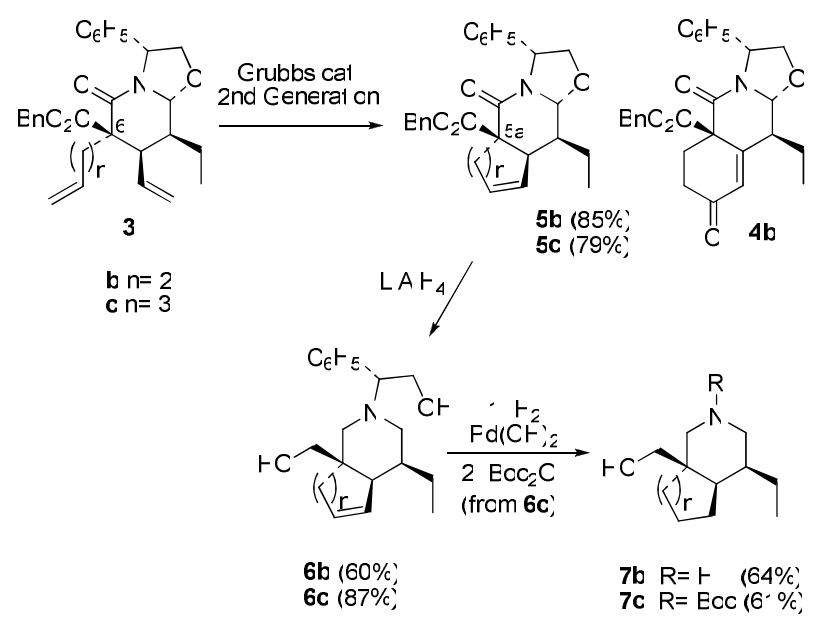

The formation of $\alpha, \beta$-unsaturated ketones $4 \mathbf{a}$ and $\mathbf{4 b}$ from alkenes $\mathbf{3 a}$ and $\mathbf{3 b}$, respectively, probably involves an initial allylic oxidation of the methine carbon at the piperidine 4-position followed by an allylic rearrangement and a subsequent oxidation. This unexpected aerial oxidation can be rationalized by considering that the change of the $\mathrm{sp}^{3}$ hybridation of the piperidine 4-carbon to $\mathrm{sp}^{2}$ relieves the strain in these highly congested trans-fused systems, in particular in the cyclopentene a series, which suffer from strong 1,3-diaxial interactions between the bulky substituent at the quaternary $\mathrm{C}-5 \mathrm{a}$ position and the ethyl substituent. ${ }^{7}$

In order to confirm this interpretation, we decided to study similar RCM reactions from dienes lacking the quaternary C-6 center. To remove the alcoxycarbonyl substituent without afecting the two carbon-carbon double bonds in the alkene moieties required for the RCM reaction, we prepared tert-butyl esters 13. This was

${ }^{7}$ For a study of the effect of strain in the spontaneous oxygenation of cyclic olefins, see: Bartlett, P. D.; Banavali, R. J. Org. Chem. 1991, 56, 6043-6050. 
performed, as outlined in Scheme 4, following a synthetic route similar to that previously developed in the above benzyloxycarbonyl series.

Scheme 4. Synthesis of the Starting Dienes in the tert-Butoxycarbonyl Series

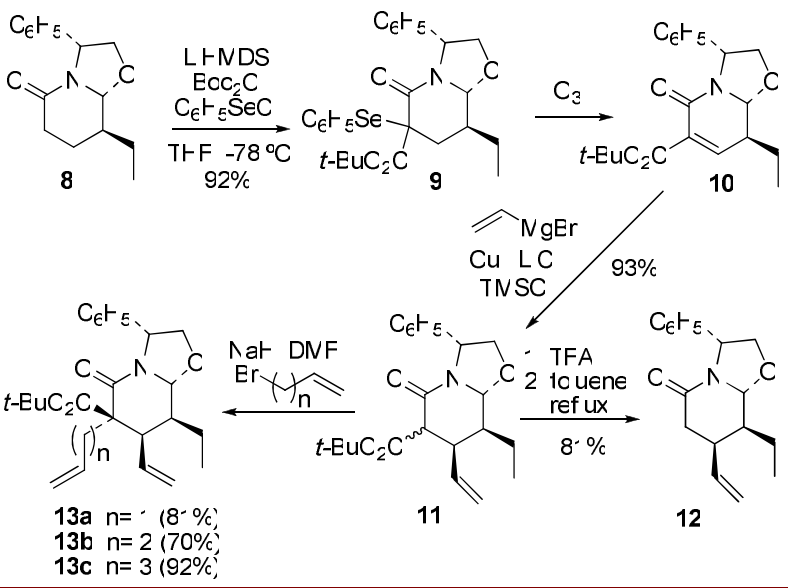

In this series, the stereoselectivity of the conjugate addition reaction was confirmed by converting the diastereoisomeric mixture of lactams $\mathbf{1 1}$ to a single oxazolopiperidone $\mathbf{1 2}$ by treatment with TFA followed by heating in refluxing toluene.

As could be expected from the above RCM reactions, and confirming the intermediacy of an allylic alcohol in the oxidation process, cyclization of diene 13a (Ar, toluene, reflux) in the presence of the second-generation Grubbs catalyst (Table 1) resulted in the spontaneous oxidation of the initially formed alkene 16a (not isolated), leading to a mixture of allylic alcohols 14a (30\%; nearly equimolecular mixture of C-7 epimers) and enone 15a (30\%) (entry 1). ${ }^{6}$ As in the above cyclizations of $\mathbf{3 b}$ and $\mathbf{3 c}$, cyclization of 13b (entry 2) and 13c (entry 3) took place in excellent yield to give the respective tricyclic lactams $\mathbf{1 6 b}$ and $16 \mathbf{c}{ }^{8}$ Catalytic hydrogenation of $\mathbf{1 6 b}$ and $16 \mathbf{c} / \mathbf{c}^{\prime}$ afforded the respective saturated lactams $\mathbf{1 7 b}$ and $\mathbf{1 7 c}$.

When the RCM reaction from diene 13b was carried out in the absence of an inert atmosphere (Table 1, entries 4 and 5), mixtures of the cyclohexene derivative $\mathbf{1 6} \mathbf{b}$ and allylic alcohols $\mathbf{1 4 b}$ were obtained. As in the above benzyloxycarbonyl series, $\mathbf{1 6} \mathbf{b}$ was oxidized ( $87 \%$ yield) to the corresponding enone $\mathbf{1 5 b}$ by heating at reflux in toluene solution. Under these conditions, alcohol 14b was similarly oxidized $(85 \%)$ to enone $\mathbf{1 5 b}$. No oxidation was observed after heating 16c/c'.

${ }^{8}$ A double bond isomerization was observed in the cyclohepta series to give mixtures of $\mathbf{c}$ and $\mathbf{c}$ ' isomers. For related isomerizations in RCM reactions, see: (a) Schmidt, B. J. Org. Chem. 2004, 69, 7672-7687. (b) Hong, S. H.; Sanders, D. P.; Lee, C. W.; Grubbs, R. H. J. Am. Chem. Soc. 2005, 127, 17160-17161. (c) Fustero, S.; Sánchez-Roselló, M.; Jiménez, D.; Sanz-Cervera, J. F.; del Pozo, C.; Aceña, J. L. J. Org. Chem. 2006, 71, 2706-2714.
Removal of the C-6 tert-butoxycarbonyl group from 13a-c was accomplished by treatment with TFA followed by heating of the resulting keto acids in refluxing toluene to give in good yields approximately 4:1 mixtures of the

Table 1. Ring-Closing Metathesis Reactions from Dienes 13

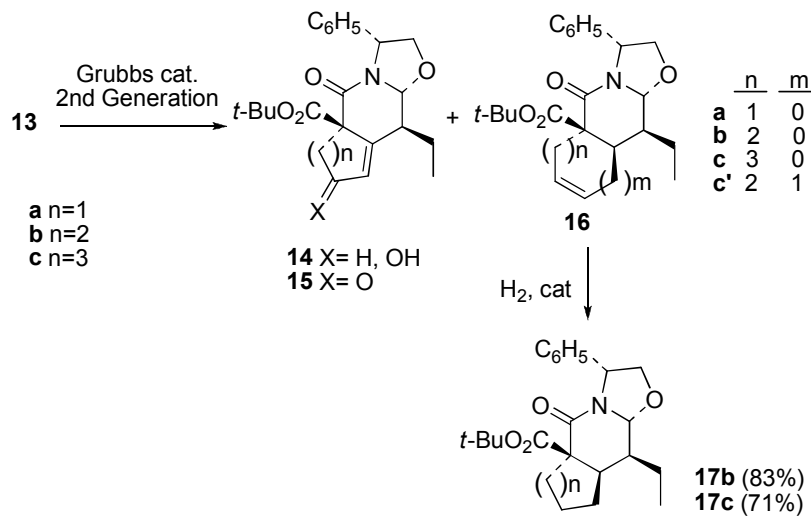

\begin{tabular}{clllc}
\hline entry & diene & solvent & argon & product $(\%)$ \\
\hline 1 & 13a & Toluene, $\Delta$ & Yes & $\mathbf{1 4 a ~}(30), \mathbf{1 5 a}(30)$ \\
2 & 13b & $\mathrm{CH}_{2} \mathrm{Cl}_{2}, \mathrm{rt}$ & Yes & $\mathbf{1 6 b}(84)$ \\
3 & $\mathbf{1 3 c}$ & Toluene, $\Delta$ & Yes & $\mathbf{1 6 c , c}(95)$ \\
4 & $\mathbf{1 3 b}$ & $\mathrm{CH}_{2} \mathrm{Cl}_{2}, \mathrm{rt}$ & No & $\mathbf{1 4 b}(24), \mathbf{1 6 b}(60)$ \\
5 & $\mathbf{1 3 b}$ & Toluene, $\Delta$ & No & $\mathbf{1 4 b}(34), \mathbf{1 6 b}(41)$
\end{tabular}

respective all-cis trisubstituted piperidine derivatives 18a-c and the corresponding C- 6 epimers.

As we had assumed, cis-fused dienes 18a-c underwent RCM reaction to give the corresponding cis-fused cycloalkenes 19a-c in excellent yields (Scheme 5). The reactions were carried out at $\mathrm{rt}$ in $\mathrm{CH}_{2} \mathrm{Cl}_{2}$ solution in series $\mathbf{a}$ and $\mathbf{b}$ but in refluxing toluene in the seven-membered

Scheme 5. Ring-Closing Metathesis Reactions in the cis-Fused Series

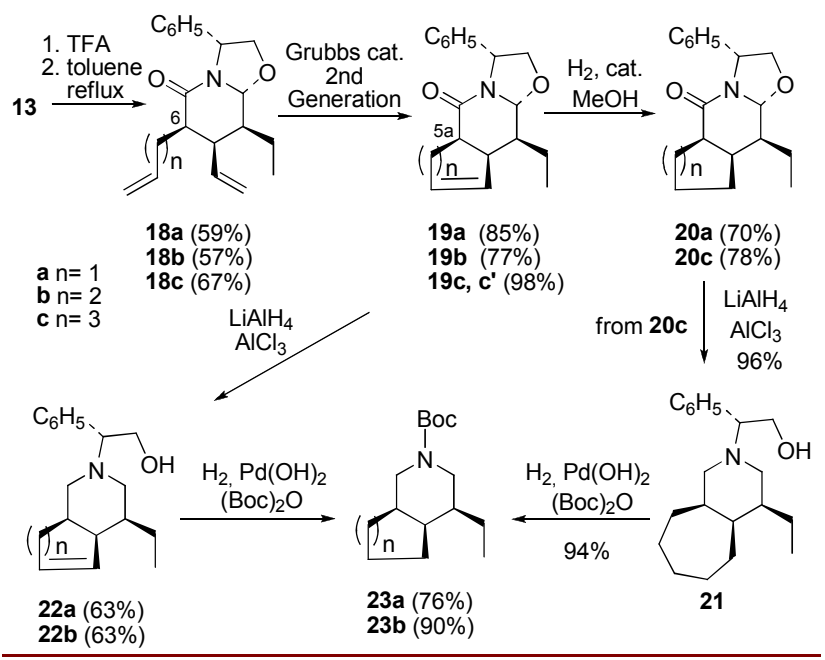


ring series $\mathbf{c}^{8}$ In no case were oxidation products detected, even when the reactions were carried out in the absence of an inert atmosphere. As outlined in Scheme 5, tricyclic lactams 19 were easily converted in excellent overall yield to the enantiopure perhydrocycloalka[c]pyridine derivatives 23a-c, thus further illustrating the synthetic potential of phenylglycinol-derived oxazolopiperidone lactams in the generation of enantiopure polysubstituted piperidine libraries. To confirm that the different behavior of diene 18a in comparison with dienes 3a and 13a in the RCM reactions can be attributed to the absence of the C- 6 alcoxycarbonyl substituent rather than to the different ring fusion in the resulting tricyclic alkenes (trans in $\mathbf{5}$ and $\mathbf{1 6}$ but cis in 19), we also studied the RCM reactions from 6epi-18a-c, which would lead to trans-fused cycloalka $[c]$ piperidines (Scheme 6). Oxidation was not observed in this series either, and the tricyclic trans-fused cycloalkenes 5a-epi-19a-c ${ }^{8}$ were isolated in excellent yields.

Scheme 6. Ring-Closing Metathesis Reactions in the trans-Fused Series
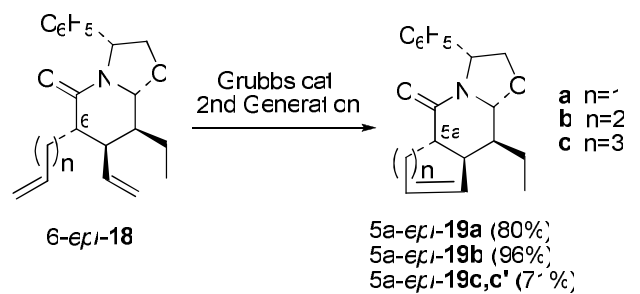

The above results demonstrate that the unexpected oxidations here reported are a consequence of the strain present in the trans-fused cycloalka[c]piperidine systems resulting from the RCM reactions. The oxidation occurs spontaneously in the highly strained cyclopenta fused derivatives, only after refluxing in toluene solution in the absence of an inert atmosphere in the less congested perhydroisoquinoline series, but it was not observed in the cyclohepta $[c]$ piperidine derivatives.

Taking into account that the 6oxocyclopenta[c]piperidine skeleton is present in a stereochemically diverse group of monoterpenoid pyridine alkaloids derived from iridodial-like presursors ${ }^{9}$ (Figure 1), starting from appropriate lactams the unexpected oxidation reported here could provide a versatile enantioselective route to these alkaloids. ${ }^{10}$

\footnotetext{
${ }^{9}$ (a) Dickinson, E. M.; Jones, G. Tetrahedron 1969, 25, 1523-1529. (b) Harris, G. H.; Fixman, E. C.; Stermitz, F. R.; Castedo, L. J. Nat. Prod. 1988, 51, 543-548. (c) Lins, A. P.; Felicio, J. D. Phytochemistry 1993, 34, 876-878. (d) Kam, T.-S.; Yoganathan, K.; Wei, C. J. Nat. Prod. 1997, 60, 673-676.

${ }^{10}$ Only one enantioselective synthesis of (+)-tecomanine has been reported: Kametani, T.; Suzuki, Y.; Ban, C.; Honda, T. Heterocycles 1987, 26, 1491-1493.
}

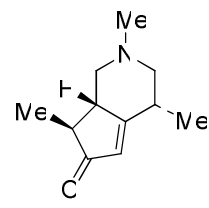

(-)-Tecoman ne

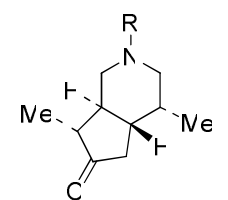

(-)-Knaba ur $n \in E$ R $=\mathrm{Ne}$ $(+,-$ Knaba ur $n \in C$ R=

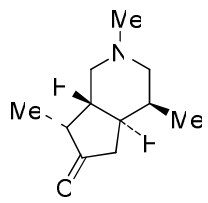

$(+,-$ Knaba ur ne E

Figure 1. Alkaloids with a 6-oxocyclopenta[c]piperidine skeleton.

Acknowledgment. Financial support from the Ministry of Education and Science, Spain (Projects CTQ200602390/BQU and CTQ2009-07021/BQU), and the AGAUR, Generalitat de Catalunya (Grants 2005-SGR-0603 and 2009-SGR-111) is gratefully acknowledged. Thanks are also due to the Ministry of Education and Science (Spain) for a fellowship to B.C., the Leonardo da Vinci programme (Unipharma Graduates-3) for a mobility grant to E.B., and Prof. Miguel Angel Miranda (Universidad Politécnica de Valencia) for his helpful comments.

Supporting Information Available. Experimental procedure for the RCM reaction from $3 \mathbf{a}$ and ${ }^{1} \mathrm{H}$ NMR and ${ }^{13} \mathrm{C}$ NMR spectra for compounds 3a-c, 4a,b, 5b,c, 7b,c, 13a-c, 14a,b, 15a,b, 16b,c, 18a-c, 6-epi-18a-c, 19a,b, 5aepi-19a-c, 20c and 23a-c. This material is available free of charge via the Internet at http://pubs.acs.org. 